\title{
IMPACTO DEL TURISMO VIVENCIAL EN EL DEPARTAMENTO DEL CUSCO CASO: PROVINCIA DE ANTA, DISTRITO DE MOLLEPATA
}

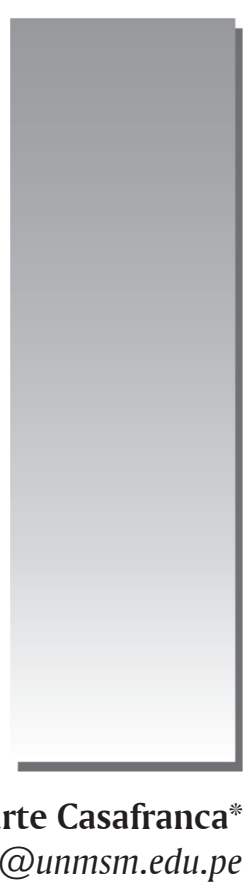

\author{
Walter David Ugarte Casafranca* \\ wugartec@unmsm.edu.pe
}

\author{
Víctor Félix Portocarrero Chávez ${ }^{* * *}$ \\ porto2202@yahoo.es
}

\begin{abstract}
RESUMEN
El Distrito de Mollepata está ubicado en la Provincia de Anta de la Región Cusco, Perú. A partir de los esfuerzos por la puesta en valor de las ruinas de Choquequirao, considerada como la "hermana sagrada de Machu Picchu” y del complejo arqueológico de Quillarumiyoc, se han desarrollado programas de incentivo del turismo alternativo en su modalidad de turismo vivencial. En esta localidad podemos encontrar, además recursos culturales notables como las festividades del Señor Manuel de la Santa Cruz de la Exaltación y la de la Sagrada Cruz de Tillca

Mollepata posee una esplendorosa producción agrícola y un circuito turístico que permite al visitante una variedad de experiencias. Éste distrito recibe alrededor de 27.000 turistas al año (según la Dirección Regional de Cultura), que permanecen uno o dos días en el lugar, ya que su objetivo es llegar a Machu Picchu. Sin embargo, presenta carencias a nivel de infraestructura de los servicios básicos que dificultan su desarrollo.
\end{abstract}

Palabras clave: Turismo Alternativo, Recurso Turístico, Cultura Andina, Turismo.

\section{ABSTRACT}

Mollepata is a district located in the province of Anta, Región Cusco, Peru. Since the efforts to enhance the ruins of Choquequirao, considered the "Machu Picchu sacred sister" and Quillarumiyoc archaeological complex, have developed incentive programs for alternative tourism in the form of experiential tourism. In this town we can find also notables cultural resources like thefestivitie of "Señor de la Exaltación",and the one of the "Holy Cross of Tillca". Mollepata has a splendid agricultural production and tours that offers to the visitors a variety of experiences. This district receives around 27,000 tourists a year (according to the Regional Directorate of Culture), which remains one or two days at the site since its objective is to reach Machu Picchu. However, it has shortcomings at the level of basic services infrastructure that hinder their development.

Keywords: Alternative Tourism, Tourist Resort , Andean Culture , Tourism.

\footnotetext{
* Abogado, Licenciado en Educaciónespecialidad Ciencias Sociales. Docente de la Facultad de Ciencias Administrativas de la UNMSM y de la Facultad de Humanidades de la UNFV.

*** Economista. Docente de la Facultad de Ciencias Administrativas de la UNMSM y de instituciones de educación superior. Egresado de Maestría en Bancas y Finanzas, Egresado de Doctorado en Administración de Empresas.
} 


\section{INTRODUCCIÓN}

El presente estudio presenta las características geográficas, culturales, históricas económicas y de recursos naturales del Distrito de Mollepata ubicado en la Provincia de Anta de la Región Cusco, Perú. Investiga los esfuerzos del gobierno local y de los pobladores para impulsar el turismo vivencial como alternativa de desarrollo de la comunidad. Esta modalidad de turismo es un proceso de encuentro y dialogo entre personas de dos culturas y vivencias diferentes, lo cual permite una interacción más auténtica entre los pobladores y los visitantes.

\section{MARCO TEÓRICO}

\section{Turismo}

El turismo es un fenómeno social que consiste en el desplazamiento voluntario y temporal de individuos o grupos de personas que fundamentalmente con motivo de recreación, descanso, cultura o salud, se trasladan de su lugar de residencia habitual a otro, y que no ejercen ninguna actividad lucrativa, generando múltiples interrelaciones de importancia social, económica y cultural. Sin embargo, el término "turismo" alude al conjunto de unidades productivas vinculadas a la actividad del turista, con lo que mantendremos la existencia de un sector económico y un conjunto de actividades, tanto empresariales como del turista, y la existencia necesaria de un conjunto de desplazamientos.

Según la Organización Mundial de Turismo (OMT, 1995) "el turismo comprende las actividades que realizan las personas durante sus viajes y estancias en lugares distintos al de su entorno habitual, por un período consecutivo inferior a un año y mayor a un día, con fines de ocio, por negocios o por otros motivos"

\section{Tipos de turismo}

La actividad turística se clasifica de acuerdo al lugar donde la actividad se va a realizar como espacio o según el propósito del viaje. Sin embargo, debemos aclarar que en una modalidad de turismo se pueden integrar una gran diversidad de actividades incluidas en otras formas de turismo.

\section{a. Turismo tradicional}

Se sustenta principalmente en el turismo masivo y en el desarrollo de grandes instalaciones de alojamiento y esparcimiento. Los turistas que practican este tipo de turismo regularmente presentan hábitos consumistas y demandan servicios sofisticados. Las actividades que mayormente lo caracterizan, la visita a playas y grandes destinos turístico o bien, a ciudades coloniales o de atractivo cultural situadas regularmente en grandes ciudades.

\section{b. Turismo gastronómico}

El turismo gastronómico es la forma en la que la gastronomía del país visitado es parte de la actividad preponderante durante su visita. El turismo gastronómico es una nueva opción de aventura, no solo dirigido a personas que gusten del arte del buen comer, como chefs o gourmets. Y también, está enfocado a todo tipo de gente que se dispone a experimentar una nueva aventura culinaria. Las actividades no se centran solo en la asistencia a restaurantes donde sirvan platos típicos, sino que abarca aspectos como la visita de mercados, tiendas de venta de productos alimenticios locales, visita a casas de los lugareños, participación en fiestas locales, etc. Uno de los objetivos de este turismo no solo es el de visitar, sino el de ser sorprendido con nuevos sabores o preparaciones culinarias.

\section{Turismo histórico cultural}

El turismo histórico-cultural comprende todos aquellos elementos y manifestaciones tangibles o intangibles producidos por las sociedades, como resultado de un proceso histórico en donde la reproducción de las ideas y del material se constituyen en factores que identifican y diferencian a ese país o región.

Ahora podemos decir que el turismo histórico cultural incluye no solo los monumentos y manifestaciones del pasado (sitios y objetos arqueológicos, arquitectura colonial e histórica, documentos y obras de arte), sino también lo que se llama patrimonio vivo; las diversas manifestaciones de la cultura popular (indígena, regional, popular, urbana), las poblaciones o comunidades tradicionales, las lenguas indígenas, las artesanías y artes populares, la indumentaria, los conocimientos, valores, costumbres y tradiciones, características de un grupo o cultura. (Buenas tareas 2010).

\section{d. Turismo alternativo}

El turismo alternativo es una nueva práctica del turismo que defiere del tradicional por ofrecer a 
los viajeros modalidades y destinos diferentes a los que ofrece el turismo comercial.

Si bien las empresas de turismo comercial empiezan a explorar nuevas modalidades como el ecoturismo, turismo de aventura, el turismo de riesgo, incluso el turismo de guerra; la verdadera esencia del turismo alternativo es el involucramiento con las poblaciones receptoras, en las actividades y los beneficios que generan el turismo, que puedan contribuir a su desarrollo, y sobre todo el calor humano que debe existir en las relaciones de los turistas con la gente y el medio geográfico.

\section{Turismo vivencial}

El turismo vivencial consiste en una modalidad de hacer turismo que tiene como particularidad que familias dedicadas principalmente a las actividades agropecuarias, deportivas y de pesca artesanal, abran sus casas para alojar al visitante, mostrándole una forma de vida única en el mundo.

Se denomina también a todas las actividades que pueden desarrollarse en el ámbito rural y que resultan de interés para los habitantes de las ciudades por sus características exóticas, románticas o diferentes a las de su habitual estilo de vida.

\section{Tipos de turismo vivencial}

\section{Agroturismo}

El turista participa activamente en actividades agropecuarias, trabajando de forma asociativa, donde también se les ofrecen vivencias características del lugar, como comida típica, bebidas propias, música autóctona, paseos, conversaciones con la gente del lugar y excursiones, con el fin de que el turista se convierta en un alto promotor del lugar. Es importante tener en cuenta que el Cusco dispone de condiciones naturales muy apropiadas para este tipo de aventura, donde dicho entorno tiene cultivos dignos de filmar y fotografiar, con un alto contenido cultural.

- Voluntariado. El turista participa de actividades de ayuda, de cooperación, en bien de la comunidad visitada. El Cusco tiene una amplia lista de opciones; antes de tomar una decisión, considere los factores del idioma, tiempo, y habilidades, para que su estancia valga la pena y le brinde mucha satisfacción. Todo contacto con las organizaciones que ofrecen estos servicios, dependen de los miembros, tales como la vivienda, alimentación, que también son factores a tomar en cuenta al momento de su elección.

- Ecoturismo. Ecoturismo o como también es llamado, "turismo verde" o "turismo de la naturaleza", es definido de la manera más simple como viajar a lugares relativamente no perturbados con el propósito de disfrutar del entorno natural.

El ecoturismo está más vinculado con el turismo de aventura en el sentido de caminar o subir cerros para contemplar el campo y apreciar las bellezas naturales desde un lugar tranquilo .Es bastante más científico Los ecoturistas quieren que se les explique cómo funcionan los ecosistemas, es decir, como se interrelacionan la flora y fauna que comparten la vida en común dentro de un nicho de vida, sea este bosque, páramo, laguna o mar.

\section{TURISMO VIVENCIAL EN LA REGIÓN CUSCO}

El turismo vivencial en el Cusco es una nueva forma de ofrecer el visitante un ambiente de calidez que le permita vivir la realidad de la zona que visita. El turismo alternativo incluye el involucramiento de las poblaciones receptoras, en las actividades y los beneficios que generan el turismo y que puedan contribuir a su desarrollo.

Mediante el turismo vivencial, se ofrece al visitante un ambiente de calidez que le permita vivir la realidad de la zona que visita, especialmente la andina, haciendo que éste se sienta como en su casa. Se intenta que el turista llegue y viva como un miembro más de la comunidad que visita, durmiendo en sus casas adecuadas para el fin, comiendo sus alimentos nativos y recorriendo sus parajes y atractivos de la comunidad.

La Región Cusco ofrece los siguientes programas de turismo vivencial:

\section{Convivencia en la comunidad de Raqchi}

El pueblo de Raqchi se encuentra a orillas del río Vilcanota, perteneciente al Distrito de San Pedro, en Cusco. Su nombre prehispánico era "Cacha". En la antiguiedad era un pueblo para diferentes propósitos, pudiendo encontrarse canchas (apartamentos), wayranas (edificios que tienen solo tres paredes), qolqas (almacenes), diferentes urnas, fuentes de agua religiosas, etc. Se cree que era un tambo importante en la ruta hacia el Collasuyo. 


\section{Convivencia en la comunidad de Willoq}

Willoq, es una comunidad indígena del Ande, ubicada en el valle del río Patacancha, perteneciente al distrito de Ollantaytambo, provincia de Urubamba, en Cusco. Es rica en flora y fauna, pudiendo encontrar 60 especies de aves y más de 700 especies de plantas. En Willoq aún se mantiene una descendencia directa de los últimos incas lo cual puede ser corroborado por los apellidos actuales de la gente del lugar, como Yupanqui, Sinchi, Pukha, Huamán, Cusipáucar, Tupha, entre otros.

\section{Convivencia en la comunidad de Q'eros}

Conocido como el último ayllu de los incas, está ubicado en la provincia de Paucartambo, en el departamento del Cusco. En Q'eros se mantiene las tradiciones incaicas, como la artesanía, medicina tradicional, festividades, rituales, comunicación a través de quipus, y su cercana relación con la tierra y sus montañas. Los pobladores son llamados altomisayoq por realizar pagos a la Pachamama.

\section{MÉTODOS}

La presente investigación es de naturaleza descriptiva y analítica. Se revisó la información bibliográfica, hemerográfica y estadística del Distrito de Mollepata, ubicado en la Región Cusco. Así mismo, se consultó la información publicada en las páginas web del Ministerio de Comercio Exterior y Turismo del Perú (Mincetur) el portal del Estado Peruano y de la Región Cusco. Se realizó un estudio de campo con la finalidad de contrastar la información obtenida con la realidad observada. Finalmente se procesó, discutió y analizó la información recopilada.

\section{RESULTADOS}

El presente estudio muestra los siguientes resultados:

- El Distrito de Mollepata cuenta con abundantes y variados recursos naturales donde se puede desarrollar nuevos productos turísticos.

- Los atractivos culturales como iglesias coloniales y otros monumentos arqueológicos han empezado a revalorarse.

- El Distrito de Mollepata cuenta con un ramal de la carretera Cusco-Lima que lo conecta a diferentes zonas urbanas y que se pueden integrar a una red vial con cada comunidad o población, lo que permite tener acceso al transporte público interprovincial.

- Gran parte de los caminos peatonales se encuentran en buen estado.

- La falta de información hace que pocos turistas lleguen a conocer la gran variedad de atractivos que existen en el Distrito de Mollepata.

- Los pobladores reconocen en el turismo una opción de negocios, y en su mayoría comprenden que el turismo genera muchas otras oportunidades de negocios y de trabajo.

- El poblador local ha empezado a comprender que las costumbres, el idioma, las festividades, así como el entorno natural son una riqueza que es necesario cuidarlos y mantenerlos.

- Carencia e ineficiencia de los servicios básicos, especialmente de los servicios higiénicos provoca incomodidad entre los visitantes.

\section{ANÁLISIS Y DISCUSIÓN}

\section{Etimología de mollepata}

La palabra Mollepata proviene de dos voces quechuas: "molle", nombre de un árbol, y "pata" significa eminencia, altura. Etimológicamente, Mollepata significa parte predominante poblada de molles Molle es el nombre de un árbol de tallo torcido y agrietado, hojas menudas y siempre verdes, flores verdosas y racimos colgantes de frutas rojizas, árbol que abundaba en el lugar.

\section{Ubicación}

Mollepata se encuentra en la parte occidental de la provincia de Anta.

\section{Límites}

Por el norte: con la provincia de La Convención.

Por el sur: con el Rio Apurímac.

Por el este: con el distrito de Limatambo.

Por el oeste: con La Convención.

\section{Extensión}

La extensión territorial del distrito de Mollepata es de $822,65 \mathrm{~km}^{2}$, se extiende desde el río blanco hasta Acobamba por el oeste; los nevados de Salkantay, Humantay y Kishuar por el norte, hasta el río Apurímac por el sur. 


\section{Reseña histórica de Mollepata}

El pueblo tiene origen inca ya que existe considerable presencia de restos monumentales arqueológicas. Así mismo, existen andenerías y caminos en diversos lugares. Mollepata en el tiempo de los incas fue un lugar debidamente organizado, en cuyo poblado se instaló un sistema de administración y control para los pobladores que les tocaba trabajar en los diversos pisos ecológicos.

Desde la invasión de los españoles en la colonia (siglos XVI, XVII y XVIII) en Mollepata hubo cambios sociales radicales bien definidos. Al frente de estas clases sociales se encontraban los españoles y sus descendientes que se volvieron los nuevos dueños de las tierras. Los indígenas quedaron marginados y arrinconados en la pobreza.

En la época republicana subsistió el feudalismo, consistente en hacer trabajar al campesino a cambio del cobijo que se le daba en las haciendas. Esto duró hasta la promulgación de la ley de Reforma Agraria (1968-1970).

Mollepata, al igual que muchos lugares del Perú, se sintió convulsionada por la Reforma Agraria lanzada por el gobierno del general Juan Velasco Alvarado. Los comuneros y los campesinos invadieron las haciendas del lugar y formaron las cooperativas que más adelante fracasaron, por lo que tuvieron que parcelar las tierras de las haciendas.

La Ley $\mathrm{N}^{\circ} 6623$, promulgada por el Ejecutivo el 29 de abril de 1929, declara a Mollepata como Distrito de la Provincia de Anta.

Hoy territorialmente comprende a las parcialidades de Abuela, Accobamba, Ayrancca, Huayrurani, Ccotomarca, Mallau, Bellavista, Tantay, Antabamba, Huamanpata, Auquiorcco, La Estrella, Marcahuasi, Huaychi, Tillca, Parobamba, Marcahuaylla, Cisal y Soray.

\section{Población}

El distrito de Mollepata tiene una población total de 3.976 habitantes.

\section{Clima}

El clima de Mollepata es variado, desde el más frígido en los nevados, templado en la parte céntrica y cálido en las orillas del rio Apurímac.

\section{Vias de comunicación}

Mollepata dispone de un ramal que se desprende de la carretera Cusco - Lima que fue construido por el hacendado de Marcahuasi, David Samanez Ocampo, con mano de obra del campesinado y sin ningún subsidio de parte del Estado.

\section{Actividades económicas}

Las principales actividades económicas del distrito de Mollepata es agricultura, ganadería y turismo. Debido a la variedad del clima tiene productos que corresponden a los tres climas como caña de azúcar, gran variedad de cereales, árboles frutales, legumbres y hortalizas.

\section{Costumbres y tradiciones}

La fiesta tradicional es la del Señor Manuel exaltacion de la Santa Cruz, que se realiza con la mayor devoción. Se caracteriza por su religiosidad, dándose prioridad al sentimiento y respeto expresado con el homenaje que se rinde. Desde el día 13 de septiembre todos los pobladores lucen sus mejores trajes de fiesta. El señor Manuel de la exaltacion de la Santa Cruz, es una bellísima escultura tallada en madera según nos dicen, de naranjo, que tiene alrededor de 1,20 m de altura y que es el patrón del distrito tambien se celebra la fiesta de la Santísima cruz de Tillca, a la que desde hace muchos años se viene rindiendo culto los días 02, 03 y 04 de mayo de cada año. Todo el pueblo realiza el peregrinaje a la cima del cerro Tillca.

\section{RECURSOS TURÍSTICOS DE MOLLEPATA}

El Distrito de Mollepata presenta diversas actividades culturales y monumentos arqueológicos alrededor de los cuales se están impulsando actividades turísticas. Es notable el afán de las autoridades para convertir estos recursos en atractivos turísticos exitosos.

\section{Choqe Churku o Choquechurco}

El nombre Choquechurco probablemente proviene de los vocablos aymara "choque", que significa oro y "Churco" que en término Quechua significa colocar, situar, encasillar, depositar, orientar, emplear, ubicar, etc. En consecuencia etimológicamente hablando Choquechurco era el lugar "donde se colocaba el oro". 
Está ubicado en la zona de amortiguamiento del conjunto arqueológico de Machu picchu, en el sector denominado Markahuaylla, en la parte superior conocida como Huancanapata, a unos 10 $\mathrm{km}$, de la población de Mollepata a $3.200 \mathrm{msnm}$ en un espacio cubierto por vegetación totalmente intrincada que con el paso del tiempo ha afectado los muros y paredes finamente labradas. Choquechurco cuenta con dos terraplenes que posiblemente eran lugares para actos ceremoniales; a unos metros se avizoran muros inca casi pandeándose por la presión de los árboles nativos como thasta, chachacomo, keuña, kiswar, molle, tara, achupalla y chillka. La zona arqueológica está prácticamente en ruinas y abandonada por falta de políticas de mantenimiento y conservación.

Desde ese lugar se puede visualizar con total amplitud todo el entorno paisajístico de los nevados Ampay, Socllaccassa, Salkantay, Umantay, parte alta de Soray, el cerro Minasmoqo desde donde se aprecia Choquekirao, Qotomarka, Tilca, Karwa, Patakarwa, Antilla, valle de Limatambo, Sauceda, abra de Huillki, Pampaconga, Pivil, Chonta y Cotabambas en Apurímac. Por estas características probablemente era una zona de dominio, posición y administración durante el imperio de los incas. Su desarrollo se habría registrado en el horizonte tardío, durante los gobiernos del inca Pachacúteq, Túpac Yupanqui o Huayna Cápac. Se caracteriza por el estilo de piedra pulida, bien ensamblada en seco y de naturaleza sólida. En Choquechurco los detalles son de piedra caliza finamente labrada, muros poligonales, paredes trapezoidales que superan el $1.80 \mathrm{~cm}$ de altura. Lo más sorprendente de este recinto es la presencia de una roca caliza de $5 \mathrm{~m}$ de diámetro, donde fue labrado un marco de $2,20 \mathrm{~cm}$ de ancho y $2,40 \mathrm{~cm}$ de altura, con algunas cornisas para sujetar posiblemente planchas de oro y plata dirigidos al saliente del dios Sol. Podría tratarse de un calendario agrícola o lugar donde se impartían señales y disposiciones que hoy son todo un misterio.

\section{La iglesia de mollepata}

La iglesia de mollepata es moderna, construida tal vez sobre una huaca incaica, como fue costumbre de los españoles para reemplazar un lugar de culto nativo por otro católico. Se ubica al lado occidental de la plaza principal del pueblo; allí, la imagen más venerada es El Señor Manuel de la exaltacion de la Santa Cruz, bellísima escultura tallada en madera.

\section{Tillka o Tilca.}

Es el nombre de un cerro puntiagudo de forma cónica, que se ubica a $4 \mathrm{~km}$ al occidente de la población de Mollepata. Es la elevación más importante en el sector, su cima fue estación de señales, punto de observación de los territorios circundantes, y observatorio astronómico; por consiguiente, fue un lugar sagrado. En la cumbre aparecen una cruz y sobre la superficie poquísimos vestigios respecto del incanato. En el flanco del cerro existen cinco andenes antiguos, y cuatro hacia el lado de Choquechurco, todos en mal estado de conservación. Tilca por su altura, ubicación y forma, atrajo la atención de los antiguos peruanos de la región, y estuvo relacionado con la actividad existente en Marcahuasi. Cristóbal de Molina "el cusqueño", en el capítulo que comenta la fiesta incaica del Situa que se realizaba en agosto o Coyaraymi, refiere que cuatro grupos de guerreros nobles recibían un mensaje del orejón que bajaba de Sacsayhuamán hasta la plaza principal de Cusco, y luego corrían portando hechos de esparto (manejo de pajas) que según su creencia, contenían o representaban a todos los males de la ciudad. Cada grupo se dirigía hacia un río principal, escapando del Cusco, por cada uno de los cuatro caminos principales, refiriéndose al grupo que corría por el sendero hacia el Chinchaysuyo.

\section{Markawasi o Marcahuasi.}

Este centro ofrece varios grupos arqueológicos como un hermoso muro antiguo con doce hornacinas, sobre el que se han construido un cobertizo que sirve de vivienda a algunos campesinos. Nos parece que se trata de la cara interna de una pared de fondo que, hoy privada de los otros muros, queda con la faz hacia el ámbito abierto. El edificio debió ser de los mejores, tal vez un palacio incaico.

Existen larguísimas paredes antiguas que dan forma a enormes explanadas rectangulares, destinadas a la explotación agropecuaria; son muros de gran calidad, de varios tipos arquitectónicos, con uniones perfectas, aunque algunos se desmoronan.

Al costado de una de las explanadas yace una gran piedra labrada por todos los lados, con un agujero circular que la atraviesa.

En toda época Marcahuasi fue un importante centro agrícola por la fertilidad de sus tierras y su buen clima. Cuenta Garcilaso de la Vega, que el 21 de enero de 1560, estando de viaje de Cusco 
a Lima para después continuar a España, pasó por una heredad "llamada Marcahuaci" a nueve leguas del Cusco, propiedad de Pedro López de Cazalla, natural de Llerena y vecino del Cusco. Allí encontró la heredad "cargada de hermosas uvas". Allí se hizo por primera vez vino de uva, en lo que corresponde a la región de Cusco.

\section{Choquequirao.}

Choquequirao (del aymarachuqi, oro, y del quechua kiraw, cuna, es decir "cuna de oro"), es una ciudad inca situada entre las estribaciones del nevado Salcantay, al sur del Perú. Los restos arqueológicos de Choquequirao están conformados por edificios y terrazas distribuidas en diferentes niveles, desde el nivel más bajo (Sunchu Pata) hasta la cima truncada más alta, la cual fue nivelada y cercada con piedras para formar una plataforma con una área aproximada de $150 \mathrm{~m}^{2}$.

Choquequirao (a veces también referida como Choqequirau o Choquekiraw) es conocida como la "hermana sagrada" de Machu Picchu por la semejanza estructural y arquitectónica con esta. Recientemente, estando parcialmente excavada, ha despertado el interés del gobierno peruano por recuperar aún más el complejo y convertirlo en una alternativa más accesible para los turistas interesados en conocer más acerca de la cultura inca.

Fue una de las puertas de ingreso hacia la región de Vilcabamba, es decir, el núcleo administrativo, político, social y económico del imperio. Así, en lo que respecta a su concepción urbana, se siguieron los patrones simbólicos de la misma capital imperial es decir, los lugares de culto al sol, a la tierra, a los ancestros, al agua y otras divinidades. Además, también se contó con residencias reales, casas de administradores y artesanos, amplios edificios para dormitorios también llamados kallancas, andenes agrícolas del Inca y del pueblo, y depósitos. De esta manera, encontramos un área ceremonial que cuenta con unos $700 \mathrm{~m}$, con un desnivel entre la plaza principal y las partes más elevadas de hasta $65 \mathrm{~m}$.

Fue desde esta edificación que los incas de la dinastía de Manco pudieron resistir la invasión española durante unos 36 años; de hecho, nunca se pudo expulsarlos de esta ciudad que solo recientemente ha cobrado su identidad desde las enmarañadas selvas del Perú.

\section{La estrella.}

Es un fundo ubicado al suroeste, abajo y muy cerca del pueblo de Mollepata, subiendo en carro por la carretera que conduce a Mollepata, se encuentra La Estrella sobre el lado izquierdo y en los últimos tramos de la vía. El fundo tiene una casa-hacienda de inmejorable ubicación; cual un pulpito colgado sobre la zona, es un mirador excepcional; el edificio es un bellísimo conjunto arquitectónico con jardines, huertas. Todo expresa elegancia y señorío, fue residencia de don David Samanez Ocampo.

\section{Llanos de soraypampa.}

Se halla al norte de Mollepata, a $3.950 \mathrm{msnm}$. Durante la época inca fue espacio ceremonial de la Huaca Salkantay. Hoy se observan en su entorno paisajístico los nevados de Umantay y Salkantay. Por su ubicación es un área apropiada para acampar, que usan los grupos de turistas que hacen la ruta a Santa Teresa, Choquequirao y Machu Picchu.

\section{ROL PROMOTOR DE LAS AUTORIDADES LOCALES}

Los funcionarios del DIRCETUR han señalado que la actividad de turismo rural comunitario no solamente conlleva a fortalecer identidades sino, básicamente, a promover desarrollo económico en bien de las familias que hoy se dedican a esta labor de manera autogestionaria, brindando servicios de calidad a los turistas.

Igualmente "la cultura inmaterial que pervive en nuestras comunidades tiene mucha relevancia en el interés de los turistas, toda vez que de manera directa pueden conocer el legado cultural de nuestros antepasados, los incas, mediante la actividades como la gastronomía, textilería, cerámica, medicina tradicional, rituales, música y demás actividades cotidianas, y que debemos seguir promocionando no solamente para el turismo receptivo sino también para el turismo interno porque muchas veces los mismos citadinos necesitamos compenetrarnos con nuestra cultura viva en las diferentes comunidades donde se realiza turismo vivencial".

Según las investigaciones del Dr. Econ. Carlos A. Dávila Rojas, el sistema de visita a la ciudadela de Choquequirao, por ser temporal y por dificultosos caminos, su explotación y beneficios, aún no están definidos e internalizados. El retraso en su puesta en valor está generando muchas pérdidas asociado a potenciales beneficios de una cadena 
articulada de inversiones y servicios con el resto de poblados aledaños impidiendo la pronta formación de otro circuito o corredor turístico en esa zona. Se debe realizar un análisis muy serio sobre la necesidad de ponerla en valor de manera masiva a través de visitas de grandes flujos de turistas vía tren y/o carretera, etc.; asociado a un uso y visitas cuidadosamente sustentables. El impacto económico de esta propuesta sería lograr que el promedio de estadía de los turistas se incremente en un día más, con sus grandes y consiguientes impactos económicos y sociales.

\section{CONCLUSIONES}

1. El turismo vivencial es una modalidad que permite el desarrollo sostenible del turismo en el Distrito de Mollepata, Provincia de Anta, Región Cusco.

2. Las autoridades locales del Distrito de Mollepata vienen realizando labores de capacitación de los pobladores en temas del sector turismo.

3. El turismo vivencial es todavía incipiente en la localidad de Mollepata.

4. El deficiente estado de la infraestructura de los servicios básicos de Mollepata impiden el desarrollo de la actividad turística.

5. El retraso en la puesta en valor de la ciudadela de Choquequirao genera el retraso del turismo en la zona.

\section{LITERATURA CITADA}

ALDONADO C. (2005) Pautas metodológicas para el análisis de experiencias de turismo comunitario, Documento de trabajo $\mathrm{n}^{\circ} 13$ de la Oficina Internacional de Trabajo, Ginebra.
BOTE GÓMEZ, Venancio (1991) “Desarrollo Turístico, su Planificación y Ubicación Geográfica": Segunda Edición, Edit. Trillas, México.

CONAM (2001) "Aportes para una Estrategia Nacional de Turismo con Énfasis en el Desarrollo Sostenible" Primera Edición. Consejo Nacional del Ambiente. Lima - Perú.

DOMINGO BEGAZO, José (2002) "Megatendencias de Turismo en el Tercer Milenio": Primera Edición, Edit. San Marcos, Lima - Perú.

HUAYÓN DALL ORTO, José Luis (2000) "Perú Turismo en el Nuevo Milenio, Proyecto Nacional II" 2da Edición Imp. Talleres Gráficos AvedecorWorld Perú S.A. Lima - Perú.

MINCETUR (2008) Plan estratégico Nacional de Turismo, PENTUR (2008-2018), Ministerio de Comercio Exterior y Turismo, Perú.

MINCETUR-AECID (2007) Desarrollo y Fortalecimiento del Turismo Rural Comunitario en el Perú, TURURAL, PERÚ, Ministerio de Comercio Exterior y Turismo, Perú.

OIT (2002) Gestión del turismo sostenible y competitivo. Alianzas entre Estado, empresa y comunidad. Los casos de Bolivia, Ecuador y Perú. OIT/Equipo Técnico Multidisciplinario para los Países Andinos, Lima.

OMT (2002) Manual on Tourism and poverty alleviation, Madrid; OMT, Madrid.

\section{PAGINAS WEB}

- http://www.peru.org.pe

- http://www.mincetur.gob.pe

- http://www.turismoruralperu.org

- http://elturismoenelcusco-2013.blogspot.com 